\title{
Outcome of lung transplantation in cystic fibrosis patients with severe asymmetric chest cavities
}

Katharina Sinn, MD, ${ }^{a}$ Theresa Stork, MD, ${ }^{\mathrm{a}}$ Stefan Schwarz, MD, ${ }^{\mathrm{a}}$ Tomaz Stupnik, MD, ${ }^{\mathrm{b}}$ Martin Kurz, MD, ${ }^{\mathrm{c}}$ Peter Jaksch, MD, PhD, ${ }^{\mathrm{a}}$ Walter Klepetko, MD, ${ }^{\mathrm{a}}$ and Konrad Hoetzenecker, MD, PhD, ${ }^{\mathrm{a}}$ the Vienna Lung Transplant Team*

\section{ABSTRACT}

Objective: A small but relevant proportion of patients with cystic fibrosis develop severely asymmetric chest cavities during the course of their disease. For these patients, the best surgical approach for lung transplantation (LTx) and optimal size matching strategies are controversial.

Methods: All cystic fibrosis patients with asymmetric chest cavities who underwent LTx at the Medical University of Vienna between 2003 and 2017 were identified $(n=13)$. Patients were grouped according to different surgical strategies: unilateral full-size and contralateral lobar transplantation $(n=4)$, standard double LTx after mobilization/repositioning of the mediastinum $(n=3)$, oversized single LTx followed by pneumonectomy on the smaller contralateral side $(n=4)$, and single LTx after a remote contralateral pneumonectomy $(n=2)$.

Results: Compared with cystic fibrosis patients with symmetric chests ( $n=276$, control group), the perioperative management of patients with asymmetric chests was often more complicated. Consequently, 90-day mortality was heightened $(23.1 \%$ vs $6.5 \%)$. Despite this, long-term survival was good with a 5 -year survival rate of $69 \%$ compared with $78 \%$. Of note, outcome seemed superior for patients who surgery was undertaken with a bilateral compared with a unilateral approach.

Conclusions: Severely asymmetric chest cavities present challenges in regard to the surgical strategy, size matching, and postoperative management. However, in carefully selected patients, LTx provides an adequate long-term outcome. (JTCVS Open 2021;8:652-63)

Cystic fibrosis (CF) is the most common life-limiting autosomal recessive disease in Europe with 1 in 2000 to 3000 children being affected. Although treatment of patients with CF has improved significantly, especially with the development of therapies targeting defects in the $\mathrm{CF}$

From the Departments of ${ }^{\mathrm{a}}$ Thoracic Surgery and ${ }^{\mathrm{c}}$ Blood Group Serology and Transfusion Medicine, Medical University of Vienna, Vienna, Austria; and ${ }^{\mathrm{b}}$ Department of Thoracic Surgery, Ljubljana University Medical Centre, Ljubljana, Slovenia.

* Members of the Vienna Lung Transplant Team include Gyoergy Lang, MD, PhD; Jose Matilla, MD; Bernhard Moser, MD, PhD; Mir Alireza Hoda, MD, PhD; Shahrokh Taghavi, MD; and Edda Tschernko, MD.

Received for publication Sept 12, 2021; accepted for publication Sept 14, 2021; available ahead of print Oct 14, 2021.

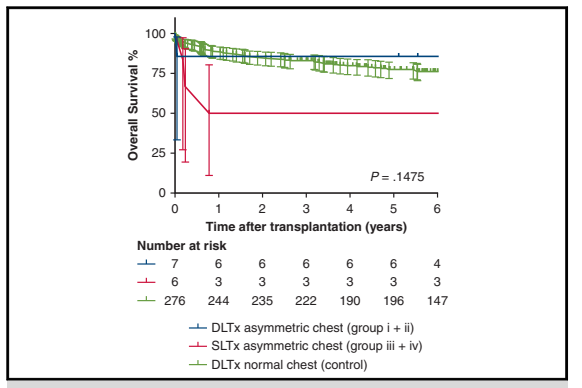

Survival rates of cystic fibrosis patients after lung transplantation.

\section{CENTRAL MESSAGE}

Lung transplantation can be offered to carefully selected CF patients with severe chest asymmetries. It provides adequate long-term outcome, especially when bilateral transplantation is feasible.

\section{PERSPECTIVE \\ Severely asymmetric chest cavities represent a challenging situation in lung transplantation. This case series shows that although the perioperative management was often complicated, long-term survival was good in carefully selected cystic fibrosis patients with asymmetric chests. Our data also suggest that-when technically feasible-a bilateral approach should be preferred. \\ See Commentaries on pages 664 and 666.}

transmembrane conductance regulator, ${ }^{1}$ average life expectancy without lung transplantation usually does not exceed the fifth decade of life. Progressive respiratory insufficiency is still the main cause of death in CF patients and lung transplantation remains the only available treatment. ${ }^{2}$

\footnotetext{
Address for reprints: Konrad Hoetzenecker, MD, PhD, Department of Thoracic Surgery, Medical University of Vienna, Waehringer Gürtel 18-20, A-1090 Vienna, Austria (E-mail: konrad.hoetzenecker@meduniwien.ac.at). 2666-2736

Copyright (C 2021 The Author(s). Published by Elsevier Inc. on behalf of The American Association for Thoracic Surgery. This is an open access article under the CC BY-NC-ND license (http://creativecommons.org/licenses/by-nc-nd/4.0/). https://doi.org/10.1016/j.xjon.2021.09.021
} 


$$
\begin{aligned}
& \text { Abbreviations and Acronyms } \\
& \begin{aligned}
\text { CF } & =\text { cystic fibrosis } \\
\text { CPB } & \text { cardiopulmonary bypass } \\
\text { CT } & =\text { computed tomography } \\
\text { DLTx } & =\text { double lung transplantation } \\
\text { ECMO } & =\text { extracorporeal membrane oxygenation } \\
\text { LTx } & \text { lung transplantation } \\
\text { PGD } & =\text { primary graft dysfunction } \\
\text { POD } & \text { postoperative day } \\
\text { SLTx } & =\text { single-lung transplantation } \\
\text { TLC } & \text { total lung capacity } \\
\text { VA } & =\text { venoarterial }
\end{aligned}
\end{aligned}
$$

A significant percentage of CF patients develop asymmetric chest cavities in the course of their disease. Prevalence of scoliosis in $\mathrm{CF}$ patients ranges from $9.9 \%$ to $15.5 \%^{3,4}$ which is 5 to 10 times higher than the frequency recorded in the general population. ${ }^{5}$ CF patients with more severe lung disease have a higher incidence of scoliosis. Because those patients are usually rejected for an orthopedic repair due to their poor pulmonary condition, progressive scoliosis often leads to secondary chest wall deformities. This may result in technical difficulties for lung transplantation (LTx). ${ }^{6}$ Another reason for asymmetric chest cavities in patients with $\mathrm{CF}$ are recurrent infections leading to atelectasis of major parts of the lung. This can result in chronic consolidation and shrinking of a lobe, a mediastinal shift, elevation of the diaphragm and consequently a significant asymmetry of 1 hemithorax.

Asymmetric chest cavities should not be considered a contraindication for LTx; however, size matching and perioperative handling can be challenging. Current literature is limited to a few case reports of CF patients with chest wall deformities and/or previous pneumonectomy receiving LTx. ${ }^{7-9}$ Of note, none of these case reports have provided long-term follow-up and survival data.

The aim of this study was to evaluate short- and longterm outcome in patients with severe asymmetric chest cavities undergoing LTx as well as to compare different surgical strategies.

\section{MATERIALS AND METHODS}

\section{Study Population and Definitions}

In this single-center, retrospective cohort study, all $\mathrm{CF}$ patients with a severe chest deformity who underwent LTx at the Medical University of Vienna between 2003 and 2017 were included. Asymmetry of the chest cavity was defined as either a significant retraction of 1 hemithorax (at least $30 \%$ smaller compared with the contralateral side), a shift of the mediastinum resulting in a big unilateral and a small contralateral thoracic cavity, or a severe scoliosis (with spinal curve $>40^{\circ}$ ). Patients with an asymmetric chest cavity seen on computed tomography (CT) scan, a history of remote pneumonectomy, or severe scoliosis were presented and discussed in our weekly pretransplant meeting, including transplant surgeons, transplant pulmonologists, psychologists, and transplant coordinators. The decision for each surgical procedure was based on the assessment of the patient's CT scan, considering the size and shape of the chest. Retransplantions as well as multiorgan and living-donor lobar transplants were excluded. Peri- and postoperative parameters were retrieved from the hospital documentation system and from the institutional transplant database. Results were compared with CF patients without chest deformities transplanted within the same time period (ie, control group). None of the control group patients received an unplanned pneumonectomy during the study period (eg, anastomotic failure, malignancy, or central pulmonary embolism with subsequent graft necrosis). In addition, we did not perform single LTx (SLTx) for CF patients with symmetric chests because SLTx should be avoided in CF patients due to the presence of highly resistant organisms and the constant risk of infectious spreading to the transplanted lung. ${ }^{10}$

Primary graft dysfunction (PGD) was calculated according to the latest recommendation of the International Society for Heart and Lung Transplantation. ${ }^{11}$ In the absence of bilateral infiltrations, a PGD0 was documented. In case of radiological signs of reperfusion edema, PGD1 was assigned when $\mathrm{PaO} 2 / \mathrm{FiO} 2(\mathrm{P} / \mathrm{F}$ ) ratio was $>300 \mathrm{~mm} \mathrm{Hg}$, PGD2 for a P/F ratio of 200 to $300 \mathrm{~mm} \mathrm{Hg}$, and PGD3 for P/F ratio $<200 \mathrm{~mm} \mathrm{Hg}$. Patients on postoperative extracorporeal membrane oxygenation (ECMO) were classified as PGD3 if chest radiograph showed bilateral infiltrations. In case of clear radiographs, ECMO patients were classified as PGD ungradable. End of mechanical ventilation was defined as extubation without early reintubation ( $<5$ days). In case of reintubation, end of mechanical ventilation was reached after the final extubation. In tracheostomized patients, end of mechanical ventilation was documented when a patient tolerated mere oxygen insufflation for more than 6 consecutive hours. The study was approved by the ethics board on human research from the Medical University of Vienna (No. EK 1264/2020). Patient written consent for the publication of the study data was waived by the institutional ethics board due to the retrospective analysis. The study rationale is summarized in Figure 1.

\section{Statistical Analysis}

Due to the small sample size, this is a mainly descriptive study. Statistical analysis was performed using SPSS version 24.0 (IBM-SPSS Inc, Armonk, NY). Normal distributed data were presented by mean and standard deviation, otherwise by median and interquartile range (IQR); categorical variables were reported by absolute frequencies and percentages. The $t$ test or Wilcoxon test were applied to test differences of continuous variables. The $\chi^{2}$ test was employed for categorical variables. The Kaplan-Meier estimate was used to calculate overall survival. Survival differences of the different subgroups were compared by long-rank tests. GraphPad Prism 8 (GraphPad Prism, GraphPad Software, La Jolla, Calif) was used to produce graphs.

\section{RESULTS}

A total of $13 \mathrm{CF}$ patients with asymmetric chests were identified (median age, 24.2 years; IQR, 18.8-31.5 years; 8 women [62\%]). Eleven patients experienced a volumereduced hemithorax with shifting of the mediastinum due to a size discrepancy of the native lungs $(n=9)$ or due to a previous pneumonectomy $(\mathrm{n}=2)$. Two patients had severe scoliosis in addition to their chest deformity. Retrospective 3-dimensional volumetry of the chest cavity $(n=6$ out of 13) was performed and the results are shown in Table E1. During the same time period, $276 \mathrm{CF}$ patients with symmetric chest cavities (median age, 24.8 years; IQR, 19.7-31.7 years; 147 women [53.3\%]) underwent transplantation and served as a control group. Detailed patient demographic characteristics are shown in Table 1. 
Asymmetric chest cavities in cystic fibrosis (CF) patients represent a challenging situation in lung transplantation (LTx). Many transplant centers are reluctant to accept these patients due to an increased perioperative risk

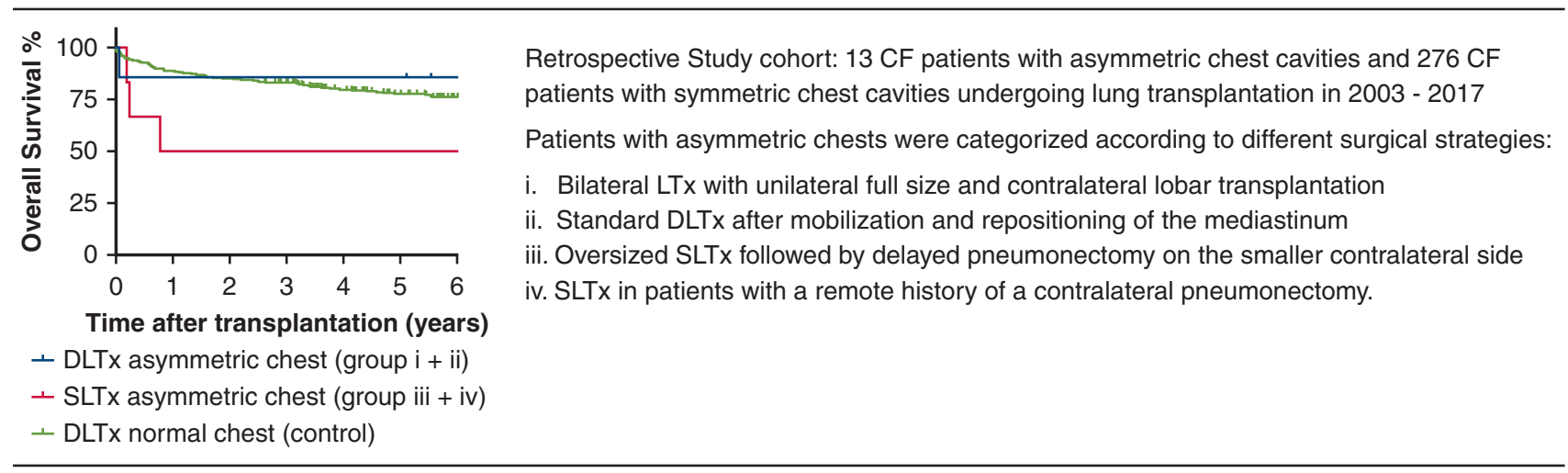

Although perioperative management was more often complicated, long-term survival was good in CF patients with asymmetric chests. A bilateral approach, if technically feasible, should be preferred

\section{(1011) MEDICAL UNIVERSITY}

FIGURE 1. Summary of rationale, key points, and conclusion of the study. This retrospective cohort study aimed to analyze outcome of cystic fibrosis ( $C F$ ) patients with asymmetric chest cavities undergoing lung transplantation $(L T x)$. Patients with asymmetric chests were grouped according to different surgical strategies and results were compared with CF patients with symmetric chests. Adequate long-term outcome can be provided for CF patients with asymmetric chest cavities, especially when bilateral transplantation is feasible. DLTX, Double-lung transplantation; SLTx, single-lung transplantation.

\section{Surgical Approach}

Patients with asymmetric chests were grouped according to the following surgical strategies: Group i: Double LTx (DLTx) with unilateral full size and contralateral lobar transplantation $(n=4)$, Group ii: Standard DLTx after mobilization and repositioning of the mediastinum $(\mathrm{n}=3)$, Group iii: Oversized SLTx followed by delayed pneumonectomy of the smaller contralateral side $(n=4)$, and Group iv: SLTx in patients who had a remote history of a contralateral pneumonectomy before they were presented to our lung transplant program $(n=2)$. CT scans of representative patients from each group are shown in Figure 2. In addition, we produced schematic drawings highlighting the different extent of chest asymmetry and the postoperative situs of each group (Figure 3). Allocation and donor selection was primarily based on donor and recipient total lung capacity (TLC). However, we measured the chest radiograph and the $\mathrm{CT}$ scan of the recipient before transplantation and adapted acceptable donor TLC ranges accordingly. Before finally accepting a donor lung, the size and shape of the donor were always evaluated during explantation by the explant surgeon.
The recipient chest was accessed through a clamshell incision in all DLTx cases $(n=7)$ or through an anterior thoracotomy in 5 of the 6 SLTx recipients. In 1 SLTx case the sternum had to be split to get sufficient access to the hilar structures. In patients of Group i (DLTx: Unilateral full size + contralateral lobe), the decision between upper or lower lobe was based on the shape of the donor lung and the space of the smaller hemithorax. In case of a relatively broad upper chest and a narrow lower chest we used the upper lobe, in case of a relatively narrow upper chest and a broad lower chest the lower lobe was used. Mobilization and repositioning of the mediastinum (Group ii) was performed by complete separation of the upper mediastinum from the sternum and the anterior chest wall. This usually results in a medialization of the heart and correction of mild to moderate size discrepancy between the 2 chest cavities. Six out of 8 DLTx patients were intraoperatively supported by a central venoarterial (VA) ECMO. Patients who underwent SLTx with a planned contralateral pneumonectomy were either transplanted on femofemoral VA ECMO $(n=3)$ or central VA ECMO $(n=1)$. The mean duration of the delayed pneumonectomy was $158.8 \pm 61.7$ minutes. The number of blood 


\begin{tabular}{|c|c|c|c|c|c|c|}
\hline & $\begin{array}{c}\text { Group i DLTx: } \\
\text { Unilateral full } \\
\text { size }+ \text { contralateral } \\
\text { lobe }(n=4)\end{array}$ & $\begin{array}{l}\text { Group ii DLTx: } \\
\text { Mediastinal } \\
\text { mobilization } \\
(\mathbf{n}=\mathbf{3})\end{array}$ & $\begin{array}{l}\text { Group iii SLTx: } \\
\text { Followed } \\
\text { by delayed } \\
\text { pneumonectomy } \\
(n=4)\end{array}$ & $\begin{array}{l}\text { Group iv SLTx: } \\
\text { Patients with } \\
\text { a remote } \\
\text { pneumonectomy } \\
(\mathrm{n}=2)\end{array}$ & $\begin{array}{l}\text { Control group } \\
\quad(n=276)\end{array}$ & $P$ value* \\
\hline \multicolumn{7}{|l|}{ Donor } \\
\hline Age (y) & $49.5(14-63)$ & $53.0(53-55)$ & $44.0(18-52)$ & $51.0(50-52)$ & $38.0(5-79)$ & .031 \\
\hline Gender $(\%)$ & & & & & & .020 \\
\hline Male & 75 & 0 & 50 & 50 & 44 & \\
\hline Female & 25 & 100 & 50 & 50 & 56 & \\
\hline Type of donation $(\%)$ & & & & & & .015 \\
\hline DBD & 100 & 100 & 100 & 100 & 97 & \\
\hline DCD & 0 & 0 & 0 & 0 & 3 & \\
\hline \multicolumn{7}{|l|}{ Smoking } \\
\hline Yes & $0(0)$ & $0(0)$ & $0(0)$ & $0(0)$ & $39(14.1)$ & .048 \\
\hline No & $3(75)$ & $2(66.7)$ & $2(50)$ & $2(100)$ & $135(48.9)$ & \\
\hline Unknown & $1(25)$ & $1(33.3)$ & $2(50)$ & $0(0)$ & $135(48.9)$ & \\
\hline Abnormal radiograph & $1(25)$ & $0(0)$ & $0(0)$ & $0(0)$ & $33(12)$ & .053 \\
\hline Last $\mathrm{Po}_{2}$ & $504.3 \pm 124.8$ & $388.7 \pm 49.7$ & $377.1 \pm 82.9$ & $466.0 \pm 22.6$ & $452.7 \pm 94.5$ & .709 \\
\hline Last $\mathrm{PCO}_{2}$ & $39.7 \pm 6.4$ & $54.2 \pm 26.6$ & $42.2 \pm 6.0$ & $52.3 \pm 16.6$ & $39.2 \pm 7.3$ & .503 \\
\hline \multicolumn{7}{|l|}{ Recipient } \\
\hline Age (y) & $18.8(17-23)$ & $30.8(22-41)$ & $30.9(28-41)$ & $20.3(16-24)$ & $24.8(6-56)$ & .854 \\
\hline Gender $(\%)$ & & & & & & .777 \\
\hline Male & 50 & 0 & 50 & 50 & 47 & \\
\hline Female & 50 & 100 & 50 & 50 & 53 & \\
\hline High urgent status & $1(25)$ & $0(0)$ & $1(25)$ & $1(50)$ & $34(12.3)$ & .331 \\
\hline LAS $\dagger$ & $51.3(37.7-64.9)$ & $37.5(-)$ & - & $62.4(-)$ & $38.8(28.6-100)$ & .906 \\
\hline Bridged with MV & $0(0)$ & $0(0)$ & $0(0)$ & $0(0)$ & $34(12.3)$ & .378 \\
\hline Bridged with ECLS & $0(0)$ & $0(0)$ & $1(25)$ & $0(0)$ & $37(13.4)$ & .690 \\
\hline \multicolumn{7}{|l|}{ Incision } \\
\hline Clamshell & $4(100)$ & $3(100 \%)$ & $0(0)$ & $1(50)$ & $276(100)$ & $<.001$ \\
\hline Thoracotomy & $0(0)$ & $0(0)$ & $4(100)$ & $1(50)$ & $0(0)$ & \\
\hline \multicolumn{7}{|l|}{ Type of support } \\
\hline No ECMO & $0(0)$ & $1(33.3)$ & $0(0)$ & $0(0)$ & $48(17.4)$ & .705 \\
\hline $\begin{array}{l}\text { Pre- and intraoperative } \\
\text { ECMO }\end{array}$ & $0(0)$ & $0(0)$ & $1(25)$ & $0(0)$ & $38(13.8)$ & \\
\hline Intraoperative ECMO & $4(100)$ & $2(66.7)$ & $3(75)$ & $0(0)$ & $188(68.1)$ & \\
\hline $\mathrm{CPB}$ & $0(0)$ & $0(0)$ & $0(0)$ & $2(100)$ & $2(0.7)$ & \\
\hline Surgical time (min) & $311.7 \pm 41.9$ & $315.3 \pm 80.5$ & $201.3 \pm 73.1$ & $285.0 \pm 28.3$ & $397.0 \pm 70.3$ & .450 \\
\hline Postoperative ECMO & $2(50)$ & $1(33.3)$ & $3(75)$ & $1(50)$ & 44 (15.9) & .003 \\
\hline \multicolumn{7}{|l|}{ Induction therapy } \\
\hline Alemtuzumab & $2(50)$ & $2(66.7)$ & $0(0)$ & $1(50)$ & $140(50.7)$ & .361 \\
\hline Antithymocyte globulin & $2(50)$ & $1(33.3)$ & $2(50)$ & $1(50)$ & $106(38.4)$ & \\
\hline No & $0(0)$ & $0(0)$ & $2(50)$ & $0(0)$ & $30(10.9)$ & \\
\hline
\end{tabular}

Values are presented as median (range), $\mathrm{n}(\%)$ or mean \pm standard deviation, unless otherwise noted. DLTx, Double lung transplantation; $S L T x$, single lung transplantation; $D B D$, donation after brainstem death; $\mathrm{DCD}$, donation after circulatory death; $\mathrm{PO}_{2}$, oxygen tension; $\mathrm{PCO}_{2}$, carbon dioxide tension; $L A S$, lung allocation score; $M V$, mechanical ventilation; $E C L S$, extracorporeal life support; $E C M O$, extracorporeal membrane oxygenation; $C P B$, cardiopulmonary bypass. $* P$ values are all asymmetric chest groups versus control group. †LAS was implemented during December 2011 in the Eurotransplant region; therefore, it is only available for patients listed after December 2011.

products administered during SLTx and delayed pneumonectomy in Group iii are presented in Table E2. Cardiopulmonary bypass (CPB) was used in the 2 SLTx patients with a previous contralateral pneumonectomy. Intraoperative parameters of all patients are summarized in Table 1.

\section{Perioperative Results}

Compared with the control group, the perioperative course was more often complicated in CF patients with an asymmetric chest. There was a significant difference in PGD grades at 72 hours (PGD0 or 1: $46.2 \%$ vs 


\section{Group i}

DLTX - unilateral full size + contralateral lobe

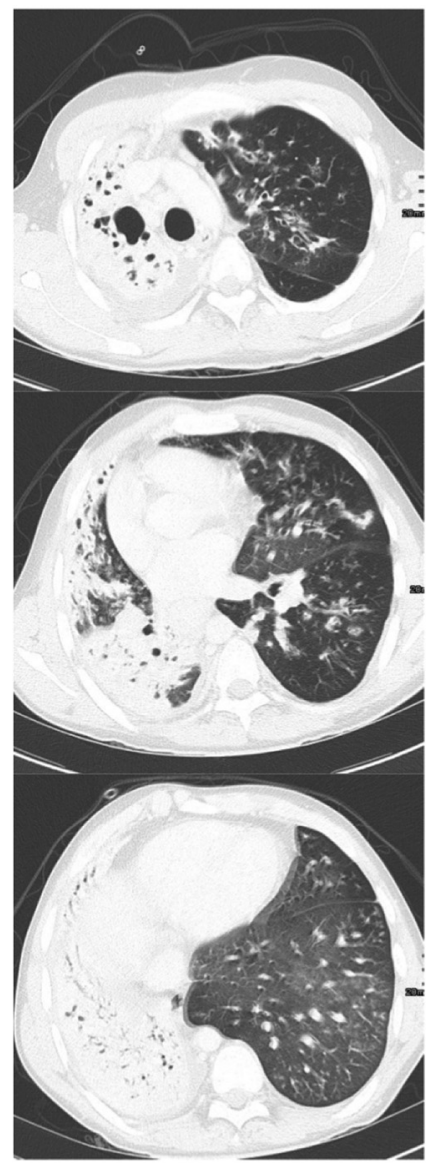

Group ii

DLTx - mediastinal

mobilization

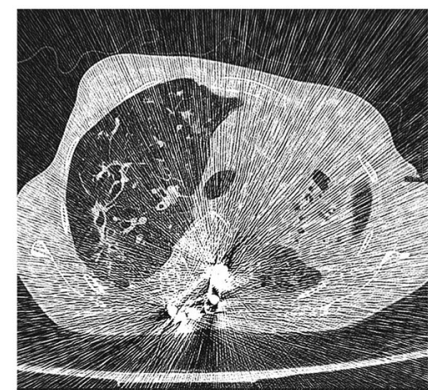

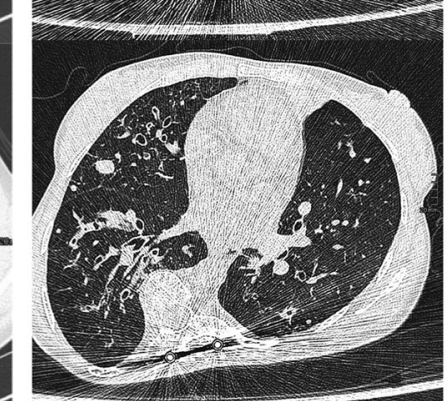

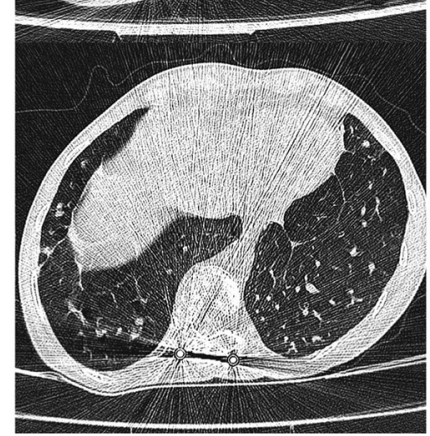

Group iii

SLTX - followed by delayed pneumonectomy

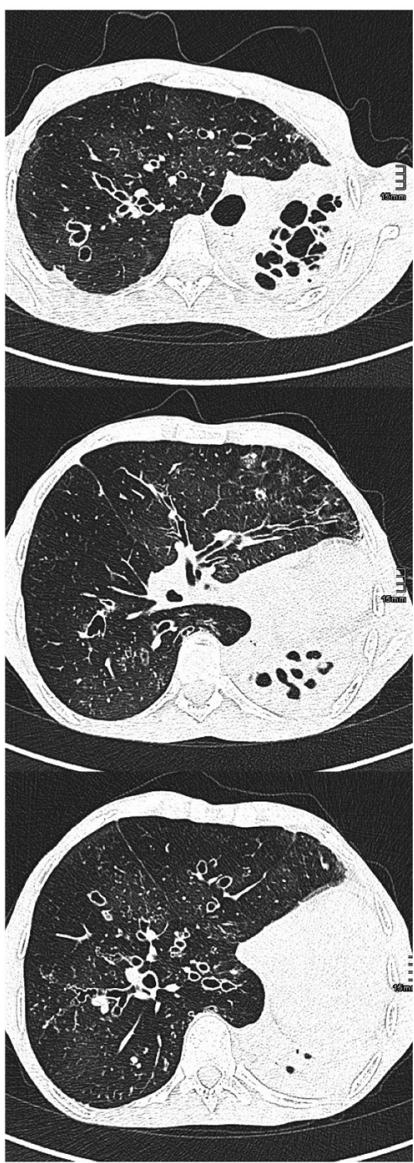

\section{Group iv}

SLTx - patients with remote pneumonectomy
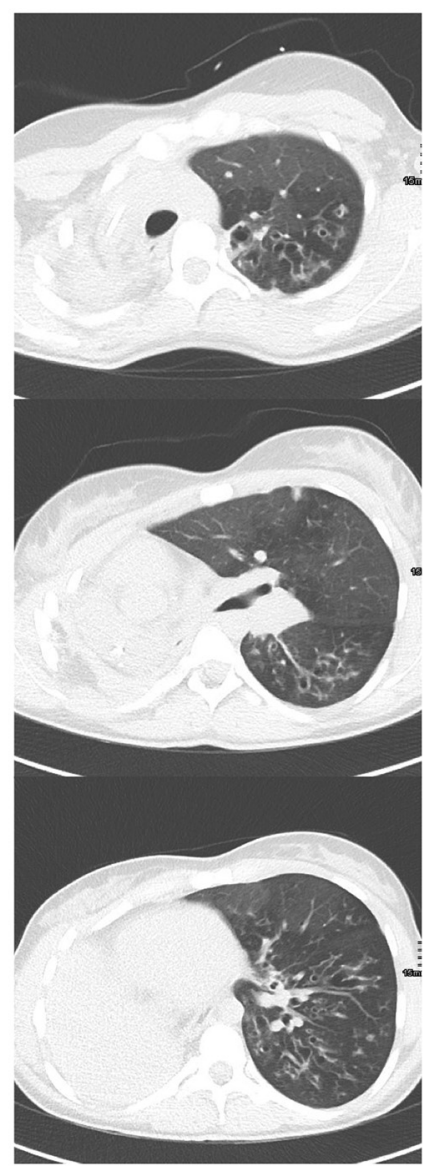

FIGURE 2. Standardized sections of preoperative computed tomography (CT) scans of representative patients with asymmetric chests. Group i: Doublelung transplantation (DLTx) with unilateral full size and contralateral lobar transplantation; Group ii: Standard DLTx after mobilization and repositioning of the mediastinum; Group iii: Oversized single-lung transplantation (SLTX) followed by delayed pneumonectomy of the smaller contralateral side; Group iv: SLTx in patients with a remote history of a contralateral pneumonectomy.

22.5\%, PGD2: $0 \%$ vs $3.6 \%$, PGD3: $23.1 \%$ vs $1.8 \%$ ) (Table 2). This translated into a prolonged duration of mechanical ventilation ( $>7$ days) in 7 out of 13 patients $(53.8 \%)$, whereas only $12.3 \%$ of patients in the control group were still ventilated on POD7. In $5(38.5 \%)$ patients, a tracheostomy was required. Three patients had to be brought back to the operating room for evacuation of a hemothorax $(\mathrm{n}=2)$ or encapsulated pleural effusion $(\mathrm{n}=1)$. CF patients with asymmetric chests required transient renal replacement therapy more often than control patients (30.8\% vs $7.3 \%)$; however, the kidney function fully recovered in all patients and none remained hemodialysis-dependent.

One patient of Group iii (SLTx with a delayed contralateral pneumonectomy) had to be listed for acute retransplantation due to severe PGD. Despite insertion of a peripheral VA ECMO, the patient did not stabilize and received a second single lung on postoperative day (POD) 3. The further course was prolonged and the pneumonectomy of the contralateral side was finally performed on POD33. The patient fully recovered and could be discharged on POD109 in good clinical condition. She lived for 15 years with an excellent quality of life and died in 2018 after a pneumonia leading to multiorgan failure.

One patient in Group i (DLTx with unilateral full-size and contralateral lobe) developed acute cellular rejection and died on POD19 after exhaustion of all therapeutic options. Two patients in Group iii (SLTx followed by delayed contralateral pneumonectomy) died on POD61 and POD86 due to infectious multiorgan failure and antibody-mediated rejection. This resulted in a 90-day mortality of $23.1 \%$ in the asymmetric chest group, which was higher compared with the control group $(6.5 \%)$. 

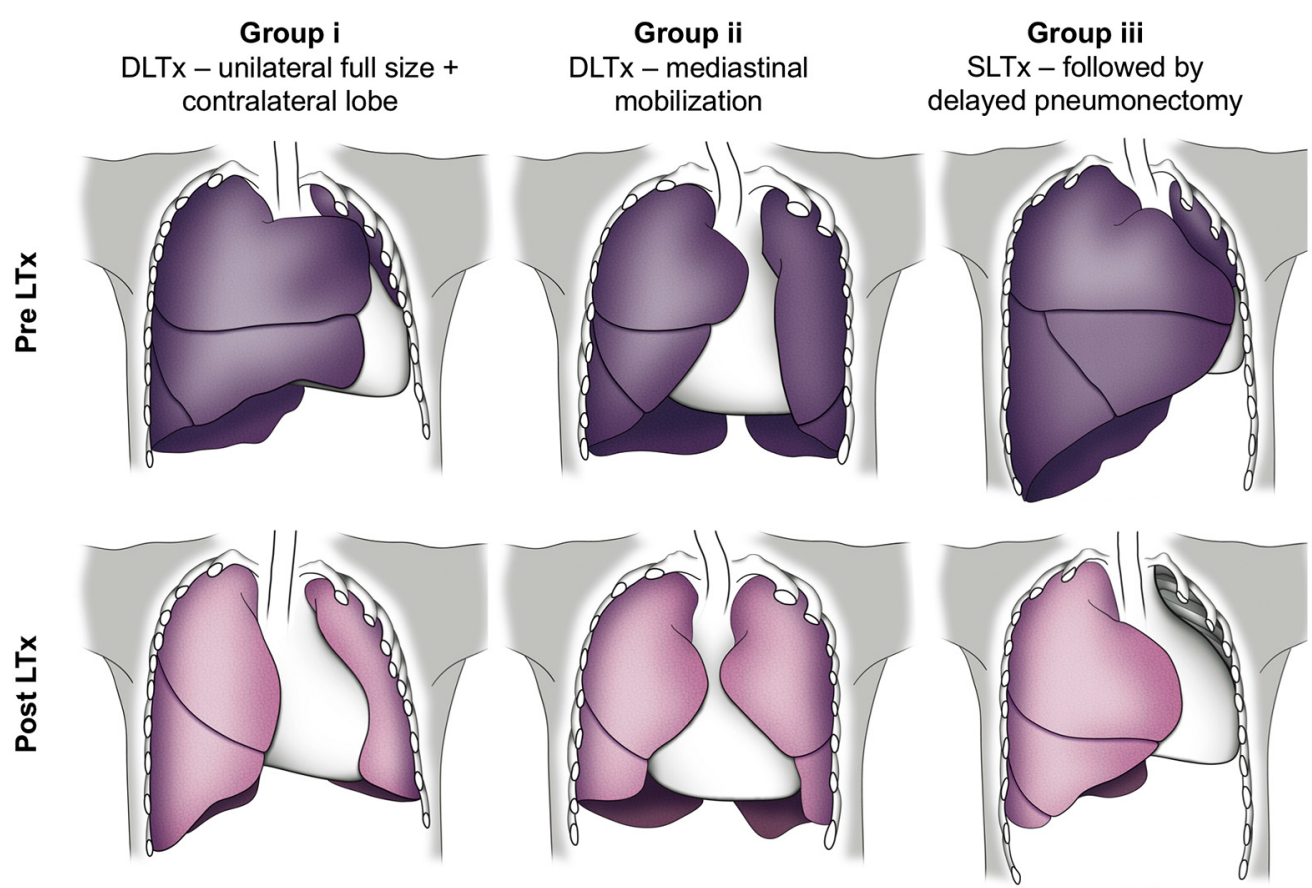
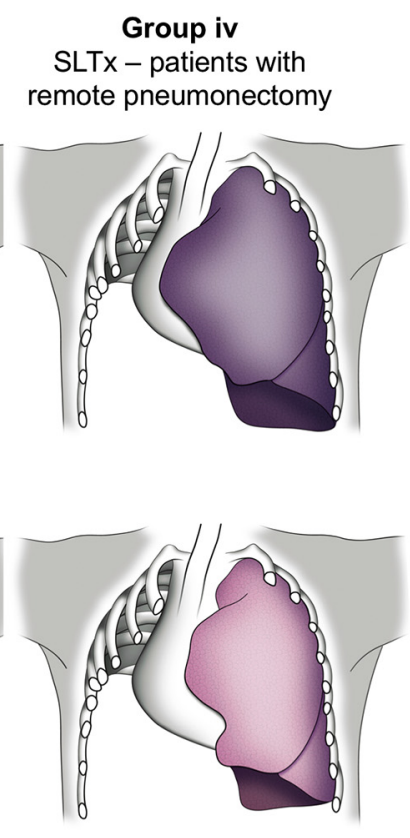

FIGURE 3. Pre- and postoperative schematic drawings of the different study groups. Group i: double-lung transplantation (DLTx) with unilateral full size and contralateral lobar transplantation; Group ii: Standard DLTx after mobilization and repositioning of the mediastinum; Group iii: Oversized single-lung transplantation (SLTX) followed by delayed pneumonectomy of the smaller contralateral side; Group iv: SLTx in patients with a remote history of a contralateral pneumonectomy. LTx, Lung transplantation.

A subanalysis of the 4 groups with asymmetric chests revealed that procedure-related complication rates as well as early outcome was significantly worse in the 2 SLTx groups. These patients had a high likelihood for prolonged mechanical ventilation, renal replacement therapy, or procedurerelated complications. Although the numbers of patients were too low to allow a meaningful statistical comparison, 2 out of 4 patients in Group iii (50\%) and 1 out of 2 in Group iv $(50 \%)$ died within 1 year after transplantation. Perioperative outcome and complications of all 4 groups are summarized in Tables 2 and 3.

\section{Long-Term Outcome}

Two patients $(15.4 \%)$ with an asymmetric chest cavity developed acute cellular rejection $>\mathrm{A} 2$ compared with 5 patients $(1.8 \%)$ in the control group. During the follow-up, $15.4 \%$ of patients in the asymmetric chest wall group developed chronic lung allograft dysfunction compared with $22.5 \%$ in the control group, the median time to the diagnosis of chronic lung allograft dysfunction was 949 days versus 1054 days.

Survival data are depicted in Figure 4. Median time of follow-up was 9.0 years (IQR, 5.6-12.0 yeras). Mean overall survival was 10.2 years (95\% confidence interval, 6.0314.38 yeras) in patients with asymmetric chest cavity versus 12.95 years (95\% confidence interval, $12.0-13.82$ years) in the control group, without any statistical significance between groups. Cause of death in CF patients with an asymmetric chest and CF patients with a symmetric chest are listed in Table 4. Detailed follow-up data of each patient in the asymmetric chest group are listed in Table E3. Although early mortality was high in the 2 SLTx groups (Group iii and Group iv), long-term survival could be achieved after overcoming the critical early postoperative period. Of note, survival in the 2 DLTx groups (Group i and Group ii) was similar to the control group. None of the long-term survivors developed late physical deformity or scoliosis.

\section{DISCUSSION}

A significant proportion of CF patients have asymmetric chest cavities due to scoliosis, chest wall deformities, or a significant mediastinal shift. Mild-to-moderate chest wall asymmetries are usually irrelevant for transplantation, but significant asymmetries make LTx challenging. Therefore, some transplant centers consider severe asymmetric chests as a contraindication for LTx. The main concerns are difficult pneumonectomy, especially in cases with a shrunken, consolidated lung; problems in finding a graft that fits to both chest cavities; and reduced chest compliance that significantly influences postoperative mucus clearance. Although sporadic case reports exist describing LTx in 


\begin{tabular}{|c|c|c|c|c|c|c|}
\hline & $\begin{array}{c}\text { Group i DLTx: } \\
\text { Unilateral full } \\
\text { size }+ \text { contralateral } \\
\text { lobe }(n=4)\end{array}$ & $\begin{array}{l}\text { Group ii DLTx: } \\
\text { Mediastinal } \\
\text { mobilization } \\
(\mathbf{n}=\mathbf{3})\end{array}$ & $\begin{array}{l}\text { Group iii SLTx: } \\
\text { Followed by delayed } \\
\text { pneumonectomy } \\
(n=4)\end{array}$ & $\begin{array}{l}\text { Group iv SLTx: } \\
\text { Patients with } \\
\text { a remote } \\
\text { pneumonectomy } \\
\quad(n=2)\end{array}$ & $\begin{array}{c}\text { Control } \\
\text { group } \\
(\mathbf{n}=\mathbf{2 7 6})\end{array}$ & $P$ value* \\
\hline \multicolumn{7}{|l|}{ PGD at $72 \mathrm{~h}$} \\
\hline PGD 0 & $1(25)$ & $2(66.7)$ & $1(25)$ & $0(0)$ & $48(17.4)$ & .003 \\
\hline PGD 1 & $0(0)$ & $0(0)$ & $1(25)$ & $1(50)$ & $14(5.1)$ & \\
\hline PGD 2 & $0(0)$ & $0(0)$ & $0(0)$ & $0(0)$ & $10(3.6)$ & \\
\hline PGD 3 & $1(25)$ & $0(0)$ & $1(25)$ & $0(0)$ & $5(1.8 \%)$ & \\
\hline PGD ungradable & $1(25)$ & $0(0)$ & $1(25)$ & $1(50)$ & $15(5.4)$ & \\
\hline Extubated & $1(25)$ & $1(33.3)$ & $0(0)$ & $0(0)$ & $183(66.3)$ & \\
\hline Tracheostomy & $0(0)$ & $1(33.3)$ & $3(75)$ & $1(50)$ & $64(23.2)$ & .200 \\
\hline $\begin{array}{l}\text { Length of mechanical } \\
\text { ventilation (d) }\end{array}$ & $2.5 \pm 2.7$ & $6.3 \pm 7.0$ & $27.8 \pm 21.0$ & $25.4 \pm 26.6$ & $3.7 \pm 6.4$ & $<.001$ \\
\hline Prolonged weaning $>7 \mathrm{~d}$ & $0(0)$ & $1(33.3)$ & $4(100)$ & $2(100)$ & $34(12.3)$ & $<.001$ \\
\hline Kidney replacement & $1(25)$ & $0(0)$ & $3(75)$ & $0(0)$ & $20(7.3)$ & .031 \\
\hline Acute re-transplantation & $0(0)$ & $0(0)$ & $1(25)$ & $0(0)$ & $0(0)$ & .045 \\
\hline ICU stay (d) & $14.3 \pm 5.0$ & $11.3 \pm 8.6$ & $49.3 \pm 28.7$ & 30 & $15.6 \pm 25.7$ & .077 \\
\hline Hospital stay (d) & $26.7 \pm 11.2$ & $35.3 \pm 23.1$ & $68.8 \pm 37.6$ & $47.5 \pm 31.8$ & $32.5 \pm 28.3$ & .150 \\
\hline 90 -d mortality rate & $1(25)$ & $0(0)$ & $2(50)$ & $0(0)$ & $18(6.5)$ & .059 \\
\hline 1 -y survival rate & $3(75)$ & $3(100)$ & $2(50)$ & $1(50)$ & $245(88.7)$ & .058 \\
\hline ACR & $1(25)$ & $0(0)$ & $1(25)$ & $0(0)$ & $5(1.8 \%)$ & .035 \\
\hline AMR & $0(0)$ & $0(0)$ & $1(25)$ & $0(0)$ & $14(50.7)$ & .507 \\
\hline CLAD & $0(0)$ & $0(0)$ & $2(50)$ & $0(0)$ & $62(22.5)$ & .307 \\
\hline
\end{tabular}

Values are presented as $\mathrm{n}(\%)$ or mean \pm standard deviation. $D L T x$, Double lung transplantation; $S L T x$, single lung transplantation; $P G D$, primary graft dysfunction; $I C U$, intensive care unit; $A C R$, acute cellular rejection; $A M R$, antibody mediated rejection; $C L A D$, chronic lung allograft dysfunction. $* P$ values: All asymmetric chest groups versus control group.

patients with asymmetric chests, there is no structured evaluation of a larger case series analyzing perioperative risks and long-term results.
This work could show that LTx can be offered to carefully selected CF patients with severe chest asymmetries. It provides adequate long-term outcome, especially when

TABLE 3. Complications

\begin{tabular}{|c|c|c|c|c|c|c|}
\hline & $\begin{array}{c}\text { Group i DLTx: } \\
\text { Unilateral full } \\
\text { size }+ \text { contralateral } \\
\text { lobe }(n=4)\end{array}$ & $\begin{array}{l}\text { Group ii DLTx: } \\
\text { Mediastinal } \\
\text { mobilization } \\
(\mathbf{n}=\mathbf{3})\end{array}$ & $\begin{array}{l}\text { Group iii SLTx: } \\
\text { Followed by } \\
\text { delayed } \\
\text { pneumonectomy } \\
(n=4)\end{array}$ & $\begin{array}{l}\text { Group iv SLTx: } \\
\text { Patients with } \\
\text { a remote } \\
\text { pneumonectomy } \\
\quad(n=2)\end{array}$ & $\begin{array}{c}\text { Control } \\
\text { group } \\
(n=276)\end{array}$ & $P$ value* \\
\hline Wound infection & $0(0)$ & $1(33.3)$ & $0(0)$ & $0(0)$ & $15(5.4)$ & .531 \\
\hline Hemothorax & $0(0)$ & $0(0)$ & $2(50)$ & $0(0)$ & $11(4.0)$ & .053 \\
\hline Pleural effusion/empyema & $0(0)$ & $1(33.3)$ & $0(0)$ & $0(0)$ & $7(2.5)$ & .268 \\
\hline DIOS/paralytic ileus & $1(25)$ & $1(33.3)$ & $1(25)$ & $0(0)$ & $6(2.7)$ & .008 \\
\hline PRES & $0(0)$ & $0(0)$ & $1(25)$ & $0(0)$ & $10(40.5)$ & .413 \\
\hline Other & $1(25)$ & $0(0)$ & $3(75)$ & $0(0)$ & $7(2.5)$ & $<.001$ \\
\hline \multicolumn{7}{|l|}{$\begin{array}{c}\text { ECMO/CPB-related } \\
\text { complications }\end{array}$} \\
\hline Groin infection & $0(0)$ & $1(50)$ & $0(0)$ & $1(50)$ & $2(0.2)$ & .259 \\
\hline Thromboembolic event & $0(0)$ & $0(0)$ & $0(0)$ & $0(0)$ & $10(4.6)$ & .467 \\
\hline Bleeding cannulation site & $0(0)$ & $0(0)$ & $1(25)$ & $0(0)$ & $0(0)$ & .098 \\
\hline
\end{tabular}

Values are presented as n (\%). DLTx, Double lung transplantation; SLTx, single lung transplantation; DIOS, distal intestinal obstruction syndrome; PRES, posterior reversible encephalopathy syndrome; $E C M O$, extracorporeal membrane oxygenation; $C P B$, cardiopulmonary bypass. ${ }^{*} P$ values: All asymmetric chest groups versus control group. 


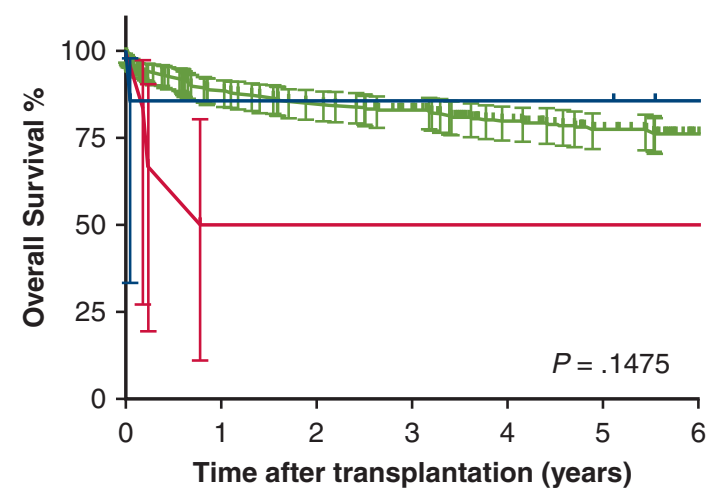

Number at risk

$\begin{array}{cccccccc}+ & 7 & 6 & 6 & 6 & 6 & 6 & 4 \\ + & 6 & 3 & 3 & 3 & 3 & 3 & 3 \\ + & 276 & 244 & 235 & 222 & 190 & 196 & 147 \\ & + \text { DLTx asymmetric chest (group i + ii) } \\ & + \text { SLTx asymmetric chest (group iii + iv) } \\ & + \text { DLTx normal chest (control) }\end{array}$

FIGURE 4. Overall survival of cystic fibrosis (CF) patients with asymmetric chests receiving double-lung transplantation (DLTx) (Group $\mathrm{I}+\mathrm{ii}$, blue) and single-lung transplantation (SLTx) (Group iii + iv, red) compared with CF patients with normal chest cavities (control group, green). There was no significant difference between the groups. Vertical bars represent $95 \%$ confidence limits.

DLTx is feasible. However, overall prognosis was significantly impaired for the subgroup of SLTx recipients.

Many patients with a long-standing chest asymmetry have a limited compliance and mucus clearance can be impaired in the early postoperative period. This can lead to prolonged respiratory weaning and recurrent infections. Early tracheostomy should be advocated in these patients. A tracheostomy helps to reduce the sedation requirement and therefore allows a gradual weaning of the ventilator and early mobilization. In addition, it facilitates removal of secretions by deep suction or bronchoscopy.

The assessment of the correct dimensions for the donor lung requires exceptional attention because typical

TABLE 4. Causes of death

\begin{tabular}{lcc}
\hline & Asymmetric chest $(\mathbf{n}=\mathbf{6})$ & Control $(\mathbf{n}=\mathbf{7 5})$ \\
\hline MOF & $4(66.6)$ & $39(52)$ \\
AMR & $1(16.7)$ & $0(0)$ \\
ACR & $1(16.7)$ & $1(1.3)$ \\
Malignancy & $0(0)$ & $7(9.3)$ \\
CLAD & $0(0)$ & $14(18.7)$ \\
Bleeding & $0(0)$ & $3(4)$ \\
Other & $0(0)$ & $7(9.3)$ \\
Unknown & $0(0)$ & $4(5.3)$ \\
\hline
\end{tabular}

Values are presented as n (\%). MOF, Multiorgan failure; $A M R$, antibody mediated rejection; $A C R$, acute cellular rejection; $C L A D$, chronic lung allograft dysfunction. parameters such as the real and predicted TLC are not sufficient for size-matching because they do not reflect anatomic conditions of the recipient. The size of the recipient's chest has to be calculated and judged based on CT scans-chest radiograph is not sufficient. For a planned SLTx, it has to be considered that due to mediastinal shifting, 1 hemithorax is much larger compared with the diminutive chest volume of the contralateral side. Thus, the donor has to be considerably taller than the recipient, so that a single lung graft can fill out the enlarged hemithorax. We retrospectively performed 3-dimensional volumetry of recipient CT scans to better quantify the volume of both chest cavities. Unfortunately, only 6 out of 13 CT scans were electronically still available. In our opinion, 3-dimensional volumetry is an interesting additional tool that can be used to determine the best surgical strategy of CF patients with asymmetric chests. However, we believe that the shape and configuration of the chest is equally important and should be considered in the decision making.

There are only few published case reports describing LTx in patients with severe asymmetric chests, including 2 cases with scoliosis from the Cleveland Clinic and 1 Chinese patient with severe mediastinal shift to the left who received a full-sized right allograft and lobar transplantation on the left side. Postoperative complications of these three patients included reoperation for bleeding and prolonged weaning; however, long-term outcome was good. ${ }^{12-14}$ This is in line with results from our cohort of DLTx recipients where we could demonstrate good long-term results and only 1 death within the first 90 days.

In this case series, patients of the DLTx groups (Groups i and ii) showed better survival compared with the SLTx groups (Groups iii and iv). Possible negative prognostic factors in patients after SLTx and contralateral pneumonectomy are worse posttransplant respiratory physiology and less lung volume, which can function as reserve in case of respiratory infection or graft rejection.

SLTx is usually contraindicated in CF patients as the remaining bronchiectatic lung inevitably endangers the graft, especially in patients who are colonized with multidrugresistant pathogens. ${ }^{15}$ Thus, the concept of SLTx combined with a contralateral pneumonectomy was developed. ${ }^{16}$ However, such a strategy was not widely adopted as it was associated with significantly worse short- and longterm outcome as compared to DLTx. However, if surgical options are limited to a SLTx due to a severe asymmetric chest cavity, pneumonectomy of the contralateral lung has to be performed. The question about the optimal timing of the pneumonectomy is crucial. SLTx with simultaneous contralateral pneumonectomy has the advantage that only 1 operation has to be performed and a spillage of bacteria to the transplanted graft is avoided, on the other hand the surgical trauma is greater and a sternal-sparing approach is hardly possible. Because many of the patients need 
intraoperative cardiopulmonary support (ECMO or even $\mathrm{CPB}$ ) there is a substantial risk of bleeding into the pneumonectomy cavity. Delayed pneumonectomy after SLTx might result in a shorter operating time and a reduced risk of bleeding. The arguments against a 2-stage approach include a second operation, which can interfere with the recovery and can lead to longer reconvalescence. The ultimate decision whether a pneumonectomy can be safely done immediately after SLTx or whether a cooling-down period of a couple of days is better, has to be left to the surgeon's discretion and the intraoperative situation.

A distinct subgroup of our study cohort are patients who had previously undergone pneumonectomy long before the patient was presented to our LTx program. To the best of our knowledge, only 1 case exists in the literature where a DLTx was performed successfully in such a patient. ${ }^{17}$ Apart from this case, there is general agreement among transplant surgeons that a SLTx is the only reasonable option. Piotrowski and colleagues ${ }^{8}$ reported in 1997 an SLTx performed 8 months after contralateral pneumonectomy in a young $\mathrm{CF}$ patient with an asymmetric chest. The postoperative course was complicated by severe reperfusion injury; however, after overcoming this complication, the patient recovered and could be discharged in good clinical condition. ${ }^{8}$ SLTx after a previous pneumonectomy is technically challenging and the following technical principles have to be considered: First, the pneumonectomy cavity should not be opened due to a high-risk of bacterial spreading which might lead to a postpneumonectomy empyema. Second, such transplants require $\mathrm{CPB}$ and in most cases the main pulmonary artery needs a vent. Third, central cannulation may be difficult due to the often extensive mediastinal shift and a peripheral cannulation should be considered. Postoperative care is also particularly demanding and holds special risks. Adequate fluid management is essential to avoid lung edema and PGD3. If a negative fluid balance cannot be achieved by conservative management, then renal replacement therapy should be liberally started. We have previously shown that an early implementation of renal replacement therapy for fluid management leads to improved pulmonary outcomes and long-term kidney function is not impaired by such an approach. ${ }^{18}$

The fact that early outcome of CF LTx recipients with chest asymmetry is lower than survival of the control CF group cannot be used to justify to exclude these patients from receiving a life-saving treatment. We believe that as long as a patient has a realistic chance to fully recover after a LTx, such a procedure should be offered. Weighing the outcomes of different indications to decide whether or not a patient can be listed is problematic and will result in only accepting easy patients with the best perioperative outcome. The key aspects to consider when accepting CF patients with severe chest asymmetry for LTx are shown in Figure E1.
This study has several limitations. First, it is a retrospective single-center study, which poses a potential bias and variabilities between different transplant centers are neglected. Furthermore, due to the long study period of almost 15 years, the study cannot account for changes in allocation standards, advances in surgical techniques, and immunosuppressive protocols. Another major limitation of this work is the small number of patients with asymmetric chests undergoing LTx. This may impair the statistical comparability of outcomes with the control group. We plan to reach out to other CF centers and provide a multiinstitutional experience with patients with asymmetric chest cavities.

\section{CONCLUSIONS}

Although our cohort of patients with asymmetric chests is small, it clearly favors a (size-reduced) bilateral over a single LTx. Despite a higher perioperative morbidity and mortality long-term survival is comparable to CF patients with symmetric chests.

\section{Conflict of Interest Statement}

The authors reported no conflicts of interest.

The Journal policy requires editors and reviewers to disclose conflicts of interest and to decline handling or reviewing manuscripts for which they may have a conflict of interest. The editors and reviewers of this article have no conflicts of interest.

\section{References}

1. Bell SC, Mall MA, Gutierrez H, Macek M, Madge S, Davies JC, et al. The future of cystic fibrosis care: a global perspective. Lancet Respir Med. 2020; $8: 65-124$.

2. Lynch JP III, Sayah DM, Belperio JA, Weigt SS. Lung transplantation for cystic fibrosis: results, indications, complications, and controversies. Semin Respir Crit Care Med. 2015;36:299-320.

3. Hathorn C, Fall A, McGurk S, Tsirikos AI, Urquhart DS. Acquisition bias may have led to acceptance of the false null hypothesis that prevalence of scoliosis is the same in cystic fibrosis as the general population. Pediatr Pulmonol. 2014;49:201.

4. Ross J, Gamble J, Schultz A, Lewiston N. Back pain and spinal deformity in cystic fibrosis. Am J Dis Child. 1987;141:1313-6.

5. Erkkila JC, Warwick WJ, Bradford DS. Spine deformities and cystic fibrosis. Clin Orthop Relat Res. 1978;146-50.

6. Mataliotakis GI, Tsirikos AI, Pearson K, Urquhart DS, Smith C, Fall A. Scoliosis surgery in cystic fibrosis: surgical considerations and the multidisciplinary approach of a rare case. Case Rep Orthop. 2016;2016:7186258.

7. Le Pimpec-Barthes F, Thomas PA, Bonnette P, Mussot S, DeFrancquen P, Hernigou A, et al. Single-lung transplantation in patients with previous contralateral pneumonectomy: technical aspects and results. Eur J Cardiothorac Surg. 2009;36:927-32.

8. Piotrowski JA, Splittgerber FH, Donovan TJ, Ratjen F, Zerkowski HR. Singlelung transplantation in a patient with cystic fibrosis and an asymmetric thorax. Ann Thorac Surg. 1997;64:1456-8.

9. Souilamas R, Mostafa A, Guillemain R, Boussaud V, Amrein C, Chevalier P. Single-lung transplantation for cystic fibrosis and metachronus pneumonectomy: case reports. Transplant Proc. 2008;40:3594-5.

10. Ramirez JC, Patterson GA, Winton TL, de Hoyos AL, Miller JD, Maurer JR. Bilateral lung transplantation for cystic fibrosis. The Toronto Lung Transplant Group. J Thorac Cardiovasc Surg. 1992;103:287-93.

11. Snell GI, Yusen RD, Weill D, Strueber M, Garrity E, Reed A, et al. Report of the ISHLT Working Group on primary lung graft dysfunction, part I: definition and 
grading - a 2016 consensus group statement of the International Society for Heart and Lung Transplantation. J Heart Lung Transplant. 2017;36:1097-103.

12. Su JW, Mason DP, Murthy SC, Budev MM, Mehta AC, Goodwin R, et al. Successful double lung transplantation in 2 patients with severe scoliosis. J Heart Lung Transplant. 2008;27:1262-4.

13. Wang Y, Chen J, Wei D, Zheng M, Zhang J, Wu B. Bilateral lung transplant for bronchiectasis in asymmetric thorax: a case report. Exp Clin Transplant. 2011;9:429-31.

14. Garcha PS, Santacruz JF, Machuzak MS, Budev MM, Mehta A. Clinical course after successful double lung transplantation in a patient with severe scoliosis. $J$ Heart Lung Transplant. 2011;30:234-5.

15. Egan TM, Detterbeck FC, Mill MR, Paradowski LJ, Lackner RP, Ogden WD, et al. Improved results of lung transplantation for patients with cystic fibrosis. J Thorac Cardiovasc Surg. 1995;109:224-34.
16. Forty J, Hasan A, Gould FK, Corris PA, Dark JH. Single lung transplantation with simultaneous contralateral pneumonectomy for cystic fibrosis. J Heart Lung Transplant. 1994;13:727-30.

17. Ris HB, Krueger T, Gonzalez M, Ferrari E, Chollet-Rivier M, Marcucci C, et al Successful bilateral lung transplantation after previous pneumonectomy. Ann Thorac Surg. 2011;91:1302-4.

18. Benazzo A, Schwarz S, Schweiger T, Frick A, Moser B, Matilla J, et al. Liberal use of hemofiltration to optimize volume status in iPAH patients does not impair long-term kidney function. J Heart Lung Transplant. 2020;39:S315.

Key Words: lung transplantation, cystic fibrosis, asymmetric chest cavities 
Key aspects to consider when accepting CF patients with severe chest asymmetry for LTx

$>$ A double lung transplantation should be preferred over single lung transplantation + pneumonectomy.

Depending on the severity of asymmetry repositioning of the mediastinum or unilateral lobar transplantation are feasible options.

In case of a single lung transplantation and a contralateral pneumonectomy, the timing of the pneumonectomy (during the same procedure vs at a later time point) depends on the intraoperative course (blood turnover, hemodynamics, etc) and the primary function of the graft.

Extensive postoperative physiotherapy and aggressive mobilization are essential in the early postoperative phase.

Early tracheostomy is recommended in case of impaired mucus clearance.

FIGURE E1. Key aspects to consider when accepting cystic fibrosis $(C F)$ patients with severe chest asymmetry for lung transplantation $(L T x)$. 
TABLE E1. Three-dimensional volumetry of preoperative computed tomography scans

\begin{tabular}{lccc}
\hline Patient & Group* & Right lung & Left lung \\
\hline 1 & i & n.a. & n.a. \\
2 & i & 1200 & 3030 \\
\hline 3 & i & n.a. & n.a. \\
4 & i & 3251 & 390 \\
\hline 5 & ii & 2310 & 1880 \\
6 & ii & n.a. & n.a. \\
7 & ii & n.a. & n.a. \\
8 & iii & 4890 & 420 \\
9 & iii & 4350 & 790 \\
10 & iii & n.a. & n.a. \\
11 & iii & n.a. & n.a. \\
12 & iv & - & 2300 \\
13 & iv & n.a. & - \\
\hline
\end{tabular}

n.a., Not available. *Groups are: (i) double lung transplantation with unilateral full size and contralateral lobar transplantation, (ii) standard double lung transplantation after mobilization and repositioning of the mediastinum, (iii) oversized single lung transplantation followed by delayed pneumonectomy of the smaller contralateral side, (iv) and Single lung transplantation in patients with a remote history of a contralateral pneumonectomy.
TABLE E3. Cause of death of cystic fibrosis patients with asymmetric chest

\begin{tabular}{lccll}
\hline Patient & Group* & Survival (d) & Status & Cause of death \\
\hline 1 & i & 1864 & Alive & \\
\hline 2 & i & 3772 & Alive & \\
\hline 3 & i & 4112 & Alive & \\
4 & i & 19 & Dead & ACR \\
\hline 5 & ii & 2025 & Alive & \\
6 & ii & 2344 & Alive & \\
7 & ii & 4126 & Dead & MOF \\
8 & iii & 61 & Dead & MOF \\
9 & iii & 86 & Dead & AMR \\
10 & iii & 4522 & Alive & \\
11 & iii & 5732 & Dead & MOF \\
12 & iv & 285 & Dead & MOF \\
13 & iv & 4429 & Alive & \\
\hline
\end{tabular}

$\overline{A C R}$, Acute cellular rejection; $M O F$, multiorgan failure; $A M R$, antibody mediated rejection. *Groups: (i) Double lung transplant with unilateral full size and contralateral lobar transplantation, (ii) standard double lung transplant after mobilization and repositioning of the mediastinum, (iii) oversized single lung transplant followed by delayed pneumonectomy of the smaller contralateral side, (iv) Single lung transplant in patients with a remote history of a contralateral pneumonectomy.
TABLE E2. Number of blood products administered intraoperatively in Group iii patients

\begin{tabular}{lcccccc}
\hline & & \multicolumn{2}{c}{$\begin{array}{c}\text { During } \\
\text { transplantation }\end{array}$} & & \multicolumn{2}{c}{$\begin{array}{c}\text { During delayed } \\
\text { pneumonectomy }\end{array}$} \\
\cline { 3 - 4 } \cline { 6 - 7 } Patient & Group* & pRBC (U) & FFP (U) & & pRBC (U) & FFP (U) \\
\hline 8 & iii & 4 & 5 & 8 & 14 \\
9 & iii & 4 & 7 & 2 & 0 \\
10 & iii & 12 & 20 & 4 & 0 \\
11 & iii & 6 & 5 & 3 & 6 \\
\hline
\end{tabular}

pRBC, Packed red blood red cells; $F F P$, fresh frozen plasma. *Group iii: Oversized single lung transplantation followed by delayed pneumonectomy of the smaller contralateral side. 